\title{
SOME NEW OSCILLATION CRITERIA FOR HIGHER-ORDER QUASI-LINEAR NEUTRAL DELAY DIFFERENTIAL EQUATIONS
}

\author{
YANYUN QIAN AND RUN XU
}

Abstract. Oscillation criteria for the higher order quasi-linear neutral delay differential equations of the form

$$
\left[r(t) \psi(u(t))\left|z^{(n-1)}(t)\right|^{\alpha-1} z^{(n-1)}(t)\right]^{\prime}+\sum_{i=1}^{m} q_{i}(t) f_{i}\left(\left|u\left(\tau_{i}(t)\right)\right|^{\alpha_{i}-1} u\left(\tau_{i}(t)\right)\right)=0,
$$

$t \geqslant t_{0}, \quad z(t)=u(t)+p(t) u(t-\sigma), \alpha>0, \alpha_{i}>0(i=1,2,3, \ldots, m)$, are established under the condition:

$$
\int_{t_{0}}^{\infty} r^{-\frac{1}{\alpha}}(s) d s=\infty \text { or } \int_{t_{0}}^{\infty} r^{-\frac{1}{\alpha}}(s) d s<\infty \text { respectively, }
$$

where $n$ is even. The obtained results improve and extend some known results in literature.

Mathematics subject classification (2010): 34K11, 34K40.

Keywords and phrases: oscillation criteria, quasi-linear, neutral type, delay, higher-order.

\section{REFERENCES}

[1] R.P. AgARWAL, S.-L. Shieh, C.-C. YeH, Oscillation criteria for second order retarded differential equations, Math. Comput. Model., 26 (1997), 1-11.

[2] J.-L. Chern, W.-C. LiAn, C.-C. YEH, Oscillation criteria for second Order half-linear differential equations with functional arguments, Publ. Math. Debrecen., 48, 3-4 (1996), 209-216.

[3] J. Dzurina, I. P. Stavroulakis, Oscillatory criteria for second order delay differential equations, Appl. Math. Comput., 140 (2003), 445-453.

[4] A. Elbert, A half-linear second order differential equation, Colloquia Math. Soc. Janos Bolyai, Qualitat. Theor. Diff. Equat., 30 (1979), 153-180.

[5] A. ELBERT, Oscillation and nonoscillation theorems for some nonlinear ordinary differential equations, In Ordinary and Partial Differential Equations, Lecture Notes in Mathematics, 964 (1982), 187212.

[6] J. K. Hale, Theory of Functional Differential Equations, Springer-Verlag, New York, 1977.

[7] G. G. HAMEDANI, Oscillation behavior of nth-order forced functional differential equations, J. Math. Anal. Appl., 195 (1995), 123-134.

[8] I. T. KIGURADZE, On the oscillatory of solutions of the equation $d^{m} u / d t^{m}+a(t)\left|u^{n}\right|$ sgnu $=0$, Mat. Sb., 65 (1964), 172-187.

[9] T. KusAno, Y. NAITO, Oscillation and nonoscillation criteria for second order quasilinear differential equations, Acta Math. Hungar., 76 (1997), 81-99.

[10] T. KUSANO, Y. NAITO, A. OGATA, Strong oscillation and nonoscillation of quasilinear differential equations of second order, Diff. Equat. Dyn. Syst., 2 (1994), 1-10.

[11] T. Kus Ano, Y. Yoshida, Nonoscillation theorems for a class of quasilinear differential equations of second order, J. Math. Anal. Appl., 189 (1995), 115-127.

[12] D. D. Mirzov, On the oscillation of a system of nonlinear differential equations, Diferencial'nye Uravnenija, 9 (1973), 581-583.

[13] D. D. Mirzov, On some analogs of Sturm's and Kneser's theorems for nonlinear systems, J. Math. Anal. Appl., 53 (1976), 418-425. 
[14] D. D. Mirzov, On the oscillation of solutions of a system of differential equations, Mat. Zametki., 23 (1978), 401-404.

[15] CH. G. Philos, A new criterion for the oscillatory and asymptotic behavior of delay differential equations, Bull. Acad. Pol. Sci. Ser. Mat., 39 (1981), 61-64.

[16] Y. G. Sun, F. W. Meng, Note on the paper of Dzurina and Stavroulakis, Appl. Math. Comput., 174 (2006), 1634-1641.

[17] S. G. Shun, Oscillation of nth-order functional differential equations, Appl. Math. Comput., 21, 3 (1991), 95-102.

[18] P. WANG, X. FU, Y. YU, Oscillations of solution for a class of higher order neutral differential equation, Appl. Math., Ser. B, 13, 4 (1998), 397-402.

[19] P. WANG, W. GE, Oscillation of a class of higher order functional differential equations with damped term, Appl. Math. Comput., 148 (2004), 351-358.

[20] P. G. WANG, K. L. TEO, Y. LIU, Oscillation properties for even order neutral equations with distributed deviating arguments, Comput. Math. Appl., 182 (2005), 290-303.

[21] R. Xu, F.W. MENG, Some new Oscillation criteria for second order quasi-linear neutral delay differential equations, Appl. Math. Comput., 182 (2006), 797-803. 